\title{
Synthesis and Optimization of AA 7175 - Zirconium Carbide (ZrC) Composites Machining Parameters
}

\author{
T. Sathish ${ }^{1, *}$ and N. Sabarirajan ${ }^{2}$ \\ ${ }^{1}$ Department of Mechanical Engineering, Saveetha School of Engineering, SIMATS, Chennai 602 105, Tamil Nadu, India \\ ${ }^{2}$ Department of Mechanical Engineering, Chendhuran College of Engineering and Technology, Pudukkottai 622507, Tamil \\ Nadu, India
}

Corresponding Author Email: sathish.sailer@gmail.com

\begin{abstract}
The airline sector mostly preferable material as aluminium and its alloy due to light weight and better resistance combatant for environmental factors. In this work mainly focusing to fabricate the aluminium matrix composites and reducing the surface roughness value of the specimen in the machining process. Initially the AA7175 with reinforcement of zirconium carbide (ZrC) particles are synthesized by the route of stir casting process, the stirring deed improve the material strength. The Design of experiments is involved to optimize the machining (CNC vertical milling) parameters such as Spindle rotational speed (2000 $\mathrm{rpm}, 2400 \mathrm{rpm}$ and $2800 \mathrm{rpm})$, Machine feed rate $(1000 \mathrm{~mm} / \mathrm{min}, 1400 \mathrm{~mm} / \mathrm{min}$ and $1800 \mathrm{~mm} / \mathrm{min})$ and depth of cut $(0.3 \mathrm{~mm}, 0.6$ $\mathrm{mm}$ and $0.9 \mathrm{~mm}$ ). The $L 27$ orthogonal array model is conducted to optimize the factors with the help of Minitab numerical analysis. This approach finds the optimal factors and reduces the surface roughness value, the microstructure examine is carried out and its image is translated to analyze the $3 D$ profilometry technique.
\end{abstract}

Keywords: AA7175, zirconium carbide, milling, reinforcement, minitab, $C N C$, stir casting Received: September-23-2020, Accepted: December-07-2020, https://doi.org/10.14447/jnmes.v24i1.a06

\section{INTRODUCTION}

In the space equipments and the airline parts manufacturing industries the material of aluminium alloy occuping a major role for consumption of fabrication parts. These alloys are extensively growth the strength of the assembly with light weight and help to form a rigid structure. Aluminium alloy possess the great mechanical and chemical properties, it proffers the exceptional tribological and corrosion properties. Now its application would be expanded to the home appliances and medical care units, in automobile sectors the aluminium alloy usage is increased twiced. The civil construction field, the structural design and interior decorative the aluminum alloys are substantially occupied due to miniumum cost cinstruction. In all materials, the aluminium alloy has easy to shaping and sizing at any form including without heating. The reinforcement is the key role of increasing the strength and mechanical properties of the materials and also alter the surface structure of the composites. The reinforcement is used to reduce the wear and improve the corrosion resistance and reduce the vibration of the material. The composite preparation is the main foundation of the research work for further conducting experimental work. The stir casting route is the best way of producing any type of composites simply and short period, in this process mainly concentrate to applying proper stirring action with maintain proper time period. Before stir casting process all the materials are cleande properly and the base material is preheated in healthy condition, the reinforced particles are weighted in correct way through digital balance. The strengthening is the one of the process of addition of the hard particles to the base material. The stir casting method preferred to obtain enhanced bonding potency of the materials with adapting of high melting temperature of the materials and applying continues stirring accomplishment.

The milling operation is used for to remove the material with using of multipoint cutter tool. The convex shape can be machined in the stir casted composite samples with influence of different process parametrs. All the above mentioned in the introduction is followed for this investigation such as synthesis and optimization of the vertical milling process parameters. Plan to obtain less surface roughness value of the AA7175 with adding of zirconium carbide particles.

\section{EXPERIMENTAL PROCEDURE}

\subsection{Materials and composition}

The AA7175 has great cracking resistance, fracture toughness and stress corrosion; it is effectively applied for aircraft application such as structural components, control valves. The constituent of chemical elements of the aluminium alloy 7175 are presented in the Table 1 . The reinforcement particles of the zirconium carbide has a ceramic hard refractory material, it has mainly used to make a tool bits and cutting tools [1]. The zirconium carbide has high melting temperature such as $3500^{\circ} \mathrm{C}$.

From the earlier literature study the process factors selected of this experiment as spindle rotational speed, machine feed rate and depth of cut [2]; all the factors and it levels are tabulated in the Table 2 . 
Table 1. Chemical elements composition of AA7175

\begin{tabular}{cc}
\hline Elements & Contribution \% \\
\hline Chromium & 0.23 \\
Copper & 1.6 \\
Zinc & 5.6 \\
Magnesium & 2.5 \\
Aluminum & 90.0 \\
\hline
\end{tabular}

Table 2. Input factors and their Levels

\begin{tabular}{ccccc}
\hline S. No & Process factors & \multicolumn{3}{c}{ Level 1Level 2Level 3 } \\
1 & Spindle rotational speed (rpm) & 2000 & 2400 & 2800 \\
2 & Machine feed rate (mm/min) & 1000 & 1400 & 1800 \\
3 & Depth of cut $(\mathrm{mm})$ & 0.3 & 0.6 & 0.9 \\
\hline
\end{tabular}

\subsection{Milling operation}

The milling operation is a material removal process and also used to make gears effectively. There are different cutters are used in a milling operation to form a various shape. In this experiment the CNC vertical milling (AMS Model) machine is used to cut the step shape efficiently. The dimensions of the machining samples are $100 \times 100 \times 30 \mathrm{~mm}$ are cut from the raw casted material, the Figure 1 illustrates the before and after machining images of the component.

(a)

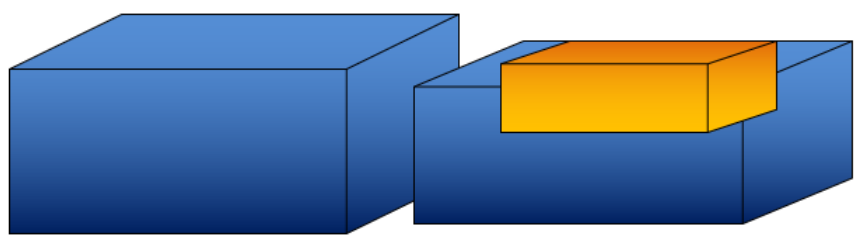

Figure 1. Images of the milling specimen (a) before machining; (b) After machining

The cemented carbide end milling cutter is selected for this work it is made up of ADDISION Tools Company. The $10 \mathrm{~mm}$ outer surface of all sides were machined by using this cutter with apply of selected parameters. All the machined surfaces are tested by the surface roughness tester of Mitutoyo product.

\section{RESULTS AND DISCUSSION}

For this investigation, the Spindle rotational speed (rpm), Machine feed rate $(\mathrm{mm} / \mathrm{min})$ and the d depth of cut $(\mathrm{mm})$ are influenced as a input factors and the response value of the surface roughness in microns are presented in the Table 3.

In the Table 4 and 5 illustrated the response table of the means and Signal to noise ratio respectively. All the factors are act together and to show the optimal output of surface roughness. These tables are analysed based on the delta values with consideration of rank order for the effect of the factors [3]. The smaller is better perception was implimented in this study because of need low surface roughness value. The depth of cut is the first rank and influenced highly, the second rank of the machining speed rate and third rank as spindle rotational speed [4]. The optimal process parameters attained of this experiment as $\mathrm{S}_{3} \mathrm{M}_{3} \mathrm{D}_{2}\left(\mathrm{~S}_{3}\right.$ - Spindle rotational speed of 2800 $\mathrm{rpm}, \mathrm{M}_{3}$ - Machining feed rate of $1800 \mathrm{~mm} / \mathrm{min}$ and $\mathrm{D}_{2}$ - Depth of cut is $0.6 \mathrm{~mm}$ )

From the main effects plot for signal to ratios, the factors influence levels are visibly showed in the Figure 2. The increasing of spindle rotational speed, machine feed rate were achieved the minimum surface roughness value, the minimum level of depth of cut increases the surface roughness value of the samples. The $0.6 \mathrm{~mm}$ depth of cut offered the lower surface roughness value.

All the graphs in a single view such as normal probability plot, versus fits plot, histogram plot and versus order plot are illustrated in a single plot as shown in Figure 3. All the four plots are clearly showed the interaction of the factors and its contribution in lying points in the plots efficiently. The normal probability plot shows the points are placed nearer to the mean line effectively. In the versus order plot the maximum points are crossed the mean line that denotes the selected parameters are excellent one.

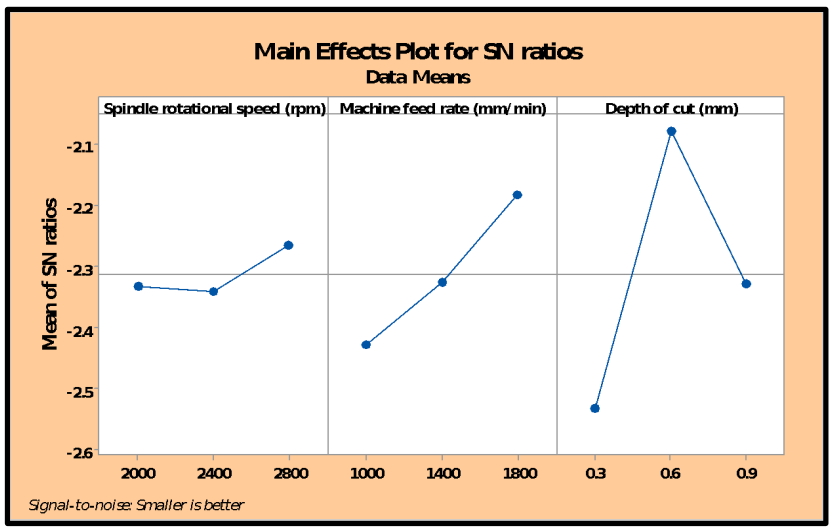

Figure 2. Image of Main effects plot for signal to ratios

Table 3. Outline of the parameters and surface roughness values

\begin{tabular}{|c|c|c|c|c|}
\hline $\begin{array}{l}\text { Exp } \\
\text { Run }\end{array}$ & $\begin{array}{c}\text { Spindle } \\
\text { rotational speed } \\
(\mathrm{rpm})\end{array}$ & $\begin{array}{l}\text { Machine feed } \\
\text { rate }(\mathrm{mm} / \mathrm{min})\end{array}$ & $\begin{array}{l}\text { Depth of } \\
\text { cut }(\mathrm{mm})\end{array}$ & $\begin{array}{c}\text { Surface } \\
\text { Roughness } \\
\text { (microns) }\end{array}$ \\
\hline 1. & 2000 & 1000 & 0.3 & 1.352 \\
\hline 2. & 2000 & 1000 & 0.3 & 1.278 \\
\hline 3. & 2000 & 1000 & 0.3 & 1.456 \\
\hline 4. & 2000 & 1400 & 0.6 & 1.215 \\
\hline 5. & 2000 & 1400 & 0.6 & 1.198 \\
\hline 6. & 2000 & 1400 & 0.6 & 1.345 \\
\hline 7. & 2000 & 1800 & 0.9 & 1.425 \\
\hline 8. & 2000 & 1800 & 0.9 & 1.135 \\
\hline 9. & 2000 & 1800 & 0.9 & 1.347 \\
\hline 10. & 2400 & 1000 & 0.6 & 1.401 \\
\hline 11. & 2400 & 1000 & 0.6 & 1.285 \\
\hline 12. & 2400 & 1000 & 0.6 & 1.234 \\
\hline 13. & 2400 & 1400 & 0.9 & 1.372 \\
\hline 14. & 2400 & 1400 & 0.9 & 1.128 \\
\hline 15. & 2400 & 1400 & 0.9 & 1.434 \\
\hline 16. & 2400 & 1800 & 0.3 & 1.236 \\
\hline 17. & 2400 & 1800 & 0.3 & 1.374 \\
\hline 18. & 2400 & 1800 & 0.3 & 1.291 \\
\hline 19. & 2800 & 1000 & 0.9 & 1.256 \\
\hline 20. & 2800 & 1000 & 0.9 & 1.353 \\
\hline 21. & 2800 & 1000 & 0.9 & 1.278 \\
\hline 22. & 2800 & 1400 & 0.3 & 1.323 \\
\hline 23. & 2800 & 1400 & 0.3 & 1.264 \\
\hline 24. & 2800 & 1400 & 0.3 & 1.458 \\
\hline 25. & 2800 & 1800 & 0.6 & 1.237 \\
\hline 26. & 2800 & 1800 & 0.6 & 1.312 \\
\hline 27. & 2800 & 1800 & 0.6 & 1.194 \\
\hline
\end{tabular}


Table 4. Response Table for Means (Surface Roughness)

\begin{tabular}{cccc}
\hline Level & $\begin{array}{c}\text { Spindle rotational } \\
\text { speed (rpm) }\end{array}$ & $\begin{array}{c}\text { Machine feed rate } \\
\text { (mm/min) }\end{array}$ & $\begin{array}{c}\text { Depth of cut } \\
\text { (mm) }\end{array}$ \\
\hline 1 & 1.306 & 1.321 & 1.337 \\
2 & 1.306 & 1.304 & 1.269 \\
3 & 1.297 & 1.283 & 1.303 \\
Delta & 0.009 & 0.038 & 0.068 \\
Rank & 3 & 2 & 1 \\
\hline
\end{tabular}

Table 5. Response Table for Signal to Noise Ratios (Surface Roughness) (Smaller is better)

\begin{tabular}{cccc}
\hline Level & $\begin{array}{c}\text { Spindle rotational } \\
\text { speed (rpm) }\end{array}$ & $\begin{array}{c}\text { Machine feed rate } \\
\text { (mm/min) }\end{array}$ & $\begin{array}{c}\text { Depth of cut } \\
\text { (mm) }\end{array}$ \\
\hline 1 & -2.332 & -2.429 & -2.532 \\
2 & -2.341 & -2.326 & -2.078 \\
3 & -2.265 & -2.184 & -2.328 \\
Delta & 0.076 & 0.245 & 0.455 \\
Rank & 3 & 2 & 1 \\
\hline
\end{tabular}

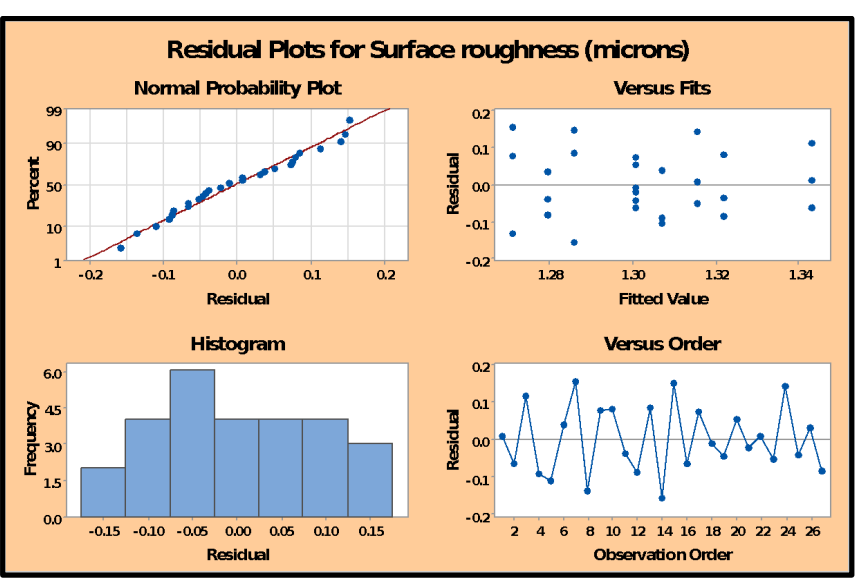

Figure 3. Image of residual plots for surface roughness

\subsection{Regression Equation}

Surface roughness (microns) $=1.429-0.000011$ Spindle rotational speed (rpm)-0.000048 Machine feed rate ( $\mathrm{mm} / \mathrm{min})-$ 0.0563 Depth of cut $(\mathrm{mm})$

The Figure 4. Shows the image of Empirical CDF of spindle rotational speed, machining feed rate, depth cut normal effeciently. The CDF of spindle rotational average speed as $2400 \mathrm{rpm}$, average of machine feed rate is $1400 \mathrm{~mm} / \mathrm{min}$ and the average depth of cut $0.6 \mathrm{~mm}$ were illustrated in the Figure 4 plainly. All the points are noted in smooth curve into the step by step movement of the graph.

The Figure 5(a) illustrates the 3D surface plot of surface roughness Vs spindle rotational speed, machining feed, the graph shows the minimum surface roughness was obtained by influencing of high spindle rotational speed and machining feed. The moderate surface rough value attained by the average of spindle rotational speedand machining feed $[5,6]$.

In the Figure 5(b) shows the surface roughness Vs machining feed, depth of cut clearly, the average depth of cut like as $0.6 \mathrm{~mm}$ and the maximum feed rate offered the minimum surface roughness of the samples.

The Figure 5(c) clearly shows the 3D surface plot of surface roughness Vs depth of cut, spindle rotational speed, the average depth of cut and the maximum spindle rotational speed produce the minimum surface roughness value. Both of the depth of cut, spindle rotational speed increases means the surface roughness value is maximized.

For clear understanding the SEM image was altered into the 2D and 3D profilometry images as shown in Figure 6(a) and Figure 6(b) respectively. In these Figures shows the surface roughness value in microns level by color identification approach, in the pink color denotes the minimum value of the surface roughness was identified. In the centre portion of the image has showed the high surface roughness value by combination of green and blue colors. The color bar was showed in the range of microns levels in variation of color indication.

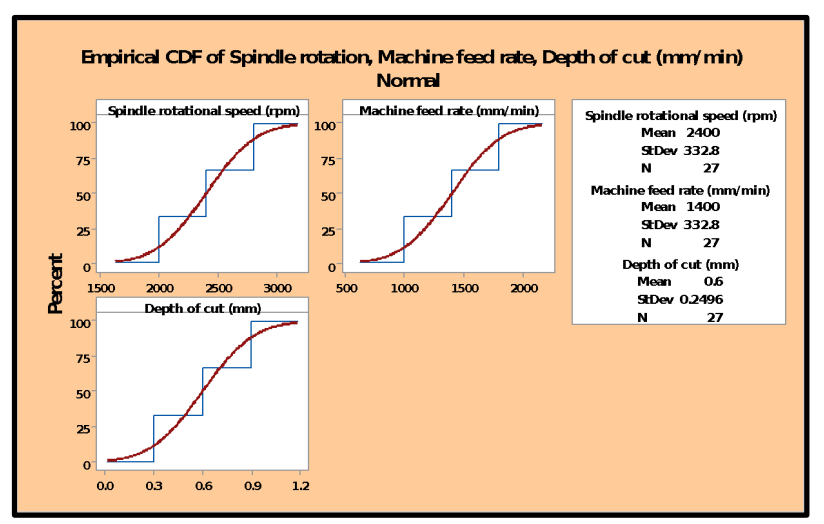

Figure 4. Image of Empirical CDF of spindle rotational speed, machining feed rate, depth cut normal

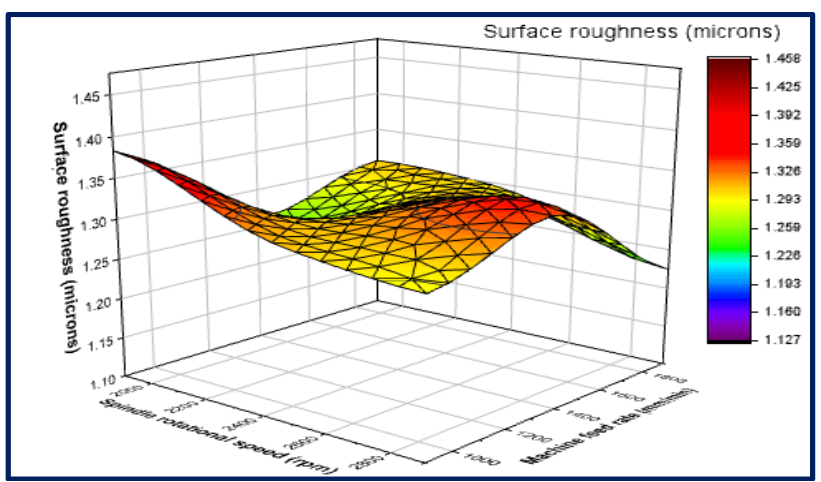

Figure 5(a). 3D surface plot of surface roughness Vs spindle rotational speed, machining feed

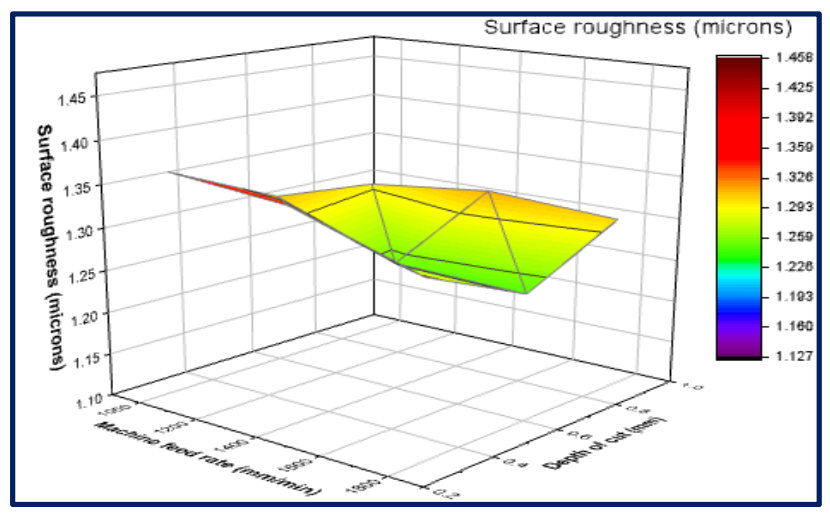

Figure 5(b). 3D surface plot of surface roughness Vs machining feed, depth of cut 


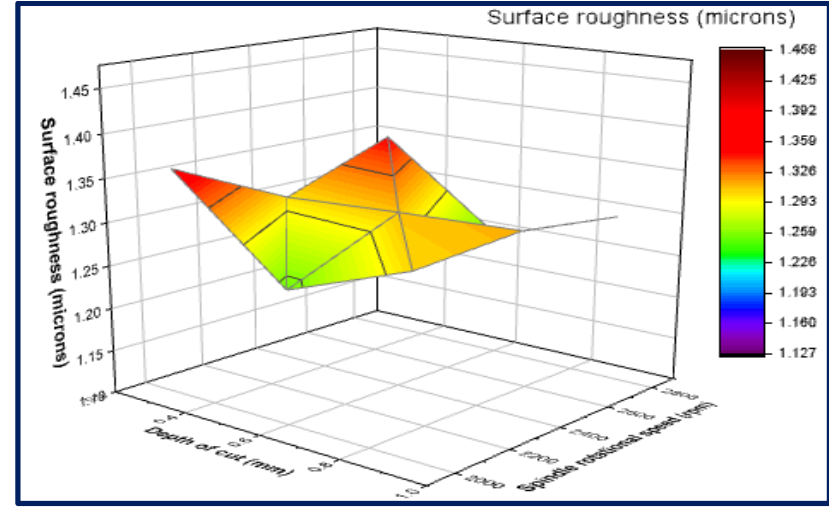

Figure 5(c). 3D surface plot of surface roughness Vs depth of cut, spindle ritational speed

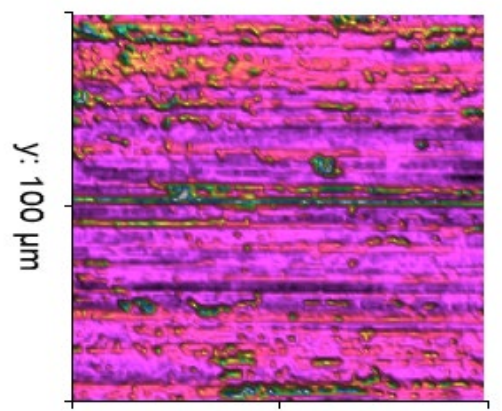

$\mathrm{x}: 100 \mu \mathrm{m}$

Figure 6(a). 2D profilometry image of the surface roughness specimen

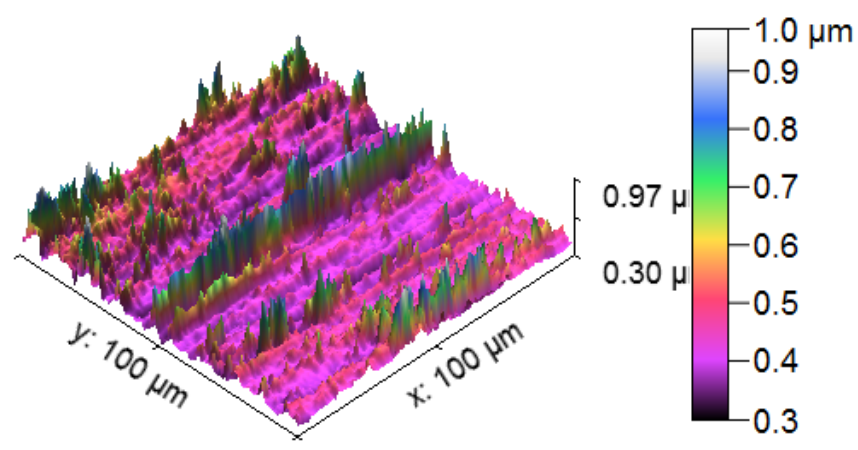

Figure 6(b). 3D profilometry image of the surface roughness specimen

\section{CONCLUSIONS}

The AA7175 and the reinforcement of zirconium carbide was stir casted through stir casting process and the composites were machined by using of CNC vertical milling machine. The surface roughness of the machined composites was analyzed by surface roughness tester the result of this optimization was concluded as follows:

- In this excperimen the depth of cut was the first rank and influenced highly, the second one of the machining speed rate and third one as spindle rotational speed. The optimal process parameters attained of this experiment as $\mathrm{S}_{3} \mathrm{M}_{3} \mathrm{D}_{2}$

- From the optimization process, the factor of depth of cut was more influenced contrast to other factors such as spindle speed and machining feed rate. The maximum of spindle speed as $2800 \mathrm{rpm}$, machining feed rate of $1800 \mathrm{rpm}$ and the depth of cut was 0.6 $\mathrm{mm}$ produced the low surface roughness value.

- In the 3D profilometry image the pink color signifies the minimum value of the surface roughness, in the centre portion of the image has showed the high surface roughness value by combination of green and blue colors.

\section{REFERENCES}

[1] Puh, F., Jurkovic, Z., Perinic, M., Brezocnik, M., Buljan, S., Tehnički Vjesnik, 23(2), 377 (2016). https://doi.org/10.17559/TV-20150526131717

[2] Maiyar, L.M., Ramanujam, R., Venkatesan, K., Jerald, J., Procedia engineering, 64, 1276 (2013). https://doi.org/10.1016/j.proeng.2013.09.208

[3] Sathish, T., Sabarirajan, N., Karthick, S., Materials Today: Proceedings, 33, 2559 (2020). https://doi.org/10.1016/j.matpr.2019.12.085

[4] Prasad, M.G., Raaj, A.A., Kumar, R.R., Gladson, F., Gautham, M., Materials Science and Engineering, 149(1), 012123 (2016). https://doi.org/10.1088/1757-899X/149/1/01212

[5] Shaik, J.H., Srinivas, J., Mechanics of Advanced Materials and Modern Processes, 3(1), 1 (2017). https://doi.org/10.1186/s40759-017-0020-6

[6] Sathish, T., Journal of Materials Research and Technology, 8(5), 4354 (2019). https://doi.org/10.1016/j.jmrt.2019.07.046 